\title{
Calprotectin Measurement
}

National Cancer Institute

\section{Source}

National Cancer Institute. Calprotectin Measurement. NCI Thesaurus. Code C82005.

The determination of the amount of calprotectin present in a sample. 